\title{
Effect of the Thermal Treatment Conditions on the Decomposition of the Metastable Phase $\beta$ in the Ti-7.5Al-2.5Mo-1.8Cr Alloy
}

\author{
By Andrzej Namysło* and Tadeusz Górecki**
}

\begin{abstract}
The course of the phase transformations upon cooling of a multicomponent titanium alloy Ti7.5Al-2.5Mo-1.8Cr has been followed by means of thermal analysis and dilatometry. The continuous cooling transformation (CCT) phase diagram has been constructed, and the effect of the cooling rate on the phase composition, microstructure and properties of the alloy has been determined by means of the X-ray diffraction, optical metallography and exoelectron emission techniques as well as by electrical resistivity, hardness and tensile tests.
\end{abstract}

(Received September 3, 1983)

Keyzeords: titanium-aluminum-molybdenum-chromium alloy, metastable beta phase, continuous cooling transformation, dilatometry, thermal analysis, exoelectron emission, mechanical properties, martensite transformation

\section{Introduction}

The alloy investigated in the present paper belongs to a broad family of the commercially available $(\alpha+\beta)$ titanium alloys. The phase composition, structure and properties of these alloys strongly depend on their chemical composition and thermal history. Depending on these factors, the $\alpha^{\prime}$ and $\alpha^{\prime \prime}$ martensite, the $\omega$ phase and in some cases intermetallic compounds $\mathrm{Ti}_{\mathrm{n}} \mathrm{X}_{\mathrm{m}}$ can be formed in the structure of $(\alpha+\beta)$ titanium alloys as a result of decomposition of the undercooled $\beta$ phase. The possibility to modulate the properties of these alloys by appropriate solution- and aging heat treatments is the reason for the remarkable research activity in the field ${ }^{(1)-(8)}$.

Early investigations of the alloys of the composition similar to that investigated in the present study ${ }^{(2)(3)(8)-(12)}$ concentrated mainly on the effect of the quenching temperature on the phase composition of the investigated materials. The mechanism and kinetics of the decomposition of metastable phases produced by quenching during subsequent ageing heat treatment have been also intensively studied. However,

* Laboratory for Materials Science, Higher School of Engineering, 45-233 Opole, Poland.

** Physics Laboratory, Higher School of Engineering, 45-370 Opole, Poland. the results reported and their interpretations are often the subject of controversy. This is because insufficient attention has been paid to the effect of the cooling rate on the transformations of the undercooled phase $\beta$ and resulting phase composition of the alloys at ambient temperature. Although the effect has been taken into account in some papers ${ }^{(3)(12)}$, the results reported are insufficient for programming the thermal treatments permitting to achieve the desired combinations of the properties of the alloys.

The present study has been undertaken with the aim to investigate the effect of the quenching temperature as well as of the rate of cooling from the $\beta$ phase region on the phase composition, structure and properties of the Ti-7.5Al$2.5 \mathrm{Mo}-1.8 \mathrm{Cr}$ alloys at room temperature. The continuous cooling phase diagram constructed as a result of the present study may be very useful for programming of thermal treatments of permitting to achieve the desired phase composition and properties of the investigated alloy.

\section{Experimental}

All the investigations were carried out using samples prepared from an industrial multicomponent $(\alpha+\beta)$ titanium alloy, supplied in the form of rods of diameter of $16 \mathrm{~mm}$.

The chemical composition of the investigated 
Table 1

\begin{tabular}{llllllllll}
\hline \hline Element & $\mathrm{Al}$ & $\mathrm{Mo}$ & $\mathrm{Cr}$ & $\mathrm{Si}$ & $\mathrm{Fe}$ & $\mathrm{Mn}$ & $\mathrm{C}$ & $\mathrm{Ti}$ \\
\hline $\begin{array}{l}\text { Content } \\
\text { in mass\% }\end{array}$ & 7.5 & 2.5 & 1.79 & 0.15 & 0.38 & 0.04 & 0.3 & balance \\
\hline \hline
\end{tabular}

material is given in Table 1.

A series of the samples were subjected to $1.8 \mathrm{ks}(0.5 \mathrm{~h})$ tempering at temperatures 850 , 900,950 and $1000^{\circ} \mathrm{C}$, followed by quenching in water at room temperature with the average cooling rate of about $46.5 \mathrm{~K} / \mathrm{s}$. Another series of specimens were heated up to $950^{\circ} \mathrm{C}$ at a rate of $0.41 \mathrm{~K} / \mathrm{s}$ and then cooled down to room temperature at various, controlled cooling rates ranging from about $19 \mathrm{~K} / \mathrm{s}$ to $0.001 \mathrm{~K} / \mathrm{s}$.

The transformations that occur during the continuous cooling as well as the decomposition of the metastable phase in the investigated alloy were detected by differential thermal analysis (DTA) and dilatometry. The effect of the thermal treatment procedure on the phase composition and structure was controlled by means of the metallographic, X-ray diffraction, resistometric and exoelectron emission techniques. The effect of the rate of continuous cooling from the $\beta$ phase region on the mechanical properties was also investigated by tension tests and hardness measurements.

The samples for the exoelectron emission and metallographic investigations have the form of disks $1.5 \mathrm{~mm}$ thick and $16 \mathrm{~mm}$ in diameter. Samples for the DTA measurements were cylinders $12 \mathrm{~mm}$ long and $3.5 \mathrm{~mm}$ in diameter. The electrical resistivity and dilatometric measurements were performed on the rods $50 \mathrm{~mm}$ long and $4 \mathrm{~mm}$ in diameter.

Absolute dilatometric measurements were performed by using a LS-4 type dilatometer. DTA measurements were carried out by using a high-temperature Linseis 62/30/80 thermoanalyser. As the standards in DTA measurements molybdenum blocks of the same dimensions as the investigated samples were used. The DTA measurements were performed in atmospheric air.

The effect of cooling rate on the electrical resistivity of the investigated alloy at room temperature has been investigated with the aid of a TMT-2 double Thomson bridge.
Measurements of the intensity of photostimulated exoelectron emission as a function of temperature were carried out by means of the arrangement described in details in a previous report $^{(13)}$. Exoelectrons were detected by means of an open air point counter with saturated quenching vapour of ethanol above the free surface of liquid ${ }^{(14)}$. The samples were not subjected to any exciting factors such as deformation and irradiation prior to measurements. The sample temperature was changed at a constant heating rate of $0.25 \mathrm{~K} / \mathrm{s}$. The surface of the sample was irradiated during the measurement with unfiltered radiation from a quartz lamp with Q-400 burner. The sample temperature was controlled using an iron-constantan thermocouple with the accuracy within $\pm 5 \mathrm{~K}$.

$\mathrm{X}$-ray diffraction patterns were taken on a DRON-2 diffractometer with filtered $\mathrm{CuK}_{\alpha}$ radiation.

Metallographic investigations were performed by using an optical microscope Neophot-2. The samples after mechanical polishing were etched in a solution composed of $10 \mathrm{~cm}^{3} \mathrm{HF}, 30 \mathrm{~cm}^{3} \mathrm{HNO}_{3}$ and $50 \mathrm{~cm}^{3} \mathrm{H}_{2} \mathrm{O}$.

\section{Results}

Metallographic examination of the structure of investigated alloy in the as delivered state revealed that it consisted of mixture of the $\alpha$ and $\beta$ phases. Heating of the alloy is accompanied by the $\alpha \rightarrow \beta$ transformation with simultaneous diffusion of the $\beta$-stabilizing alloying elements to the grains of newly formed $\beta$-phase. Dilatometric investigations indicate that at the heating rate of $0.41 \mathrm{~K} / \mathrm{s}$ the $\alpha \rightarrow \beta$ transformation begins at temperature $\mathrm{A}_{\alpha+\beta \rightarrow \beta}^{\mathrm{s}}$ being equal to about $820^{\circ} \mathrm{C}$ and ends at $\mathrm{A}_{\alpha+\beta \rightarrow \beta}^{\mathrm{F}} \approx 940^{\circ} \mathrm{C}$ (Fig. 1). Above $A^{F}$ the structure of the investigated alloy contains only the $\beta$ phase. Subsequent continuous cooling of the alloy is accompanied by decomposition of the $\beta$ phase to various phases of different morphology. The 
mechanism and kinetics of this process as well as the phase composition of the alloy after cool-

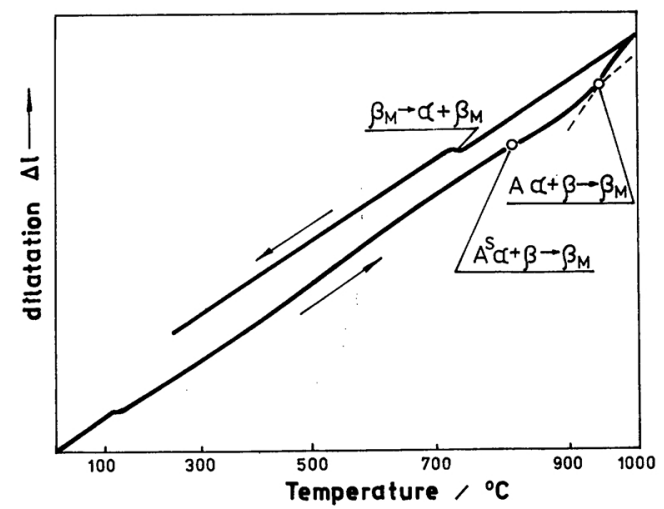

Fig. 1 Dilatometric curve for the $\mathrm{Ti}-7.5 \mathrm{Al}-2.5 \mathrm{Mo}-$ $1.8 \mathrm{Cr}$ alloy registered during heating at a rate of $0.41 \mathrm{~K} / \mathrm{s}$ and subsequent cooling at a rate of $0.83 \mathrm{~K} / \mathrm{s}$.

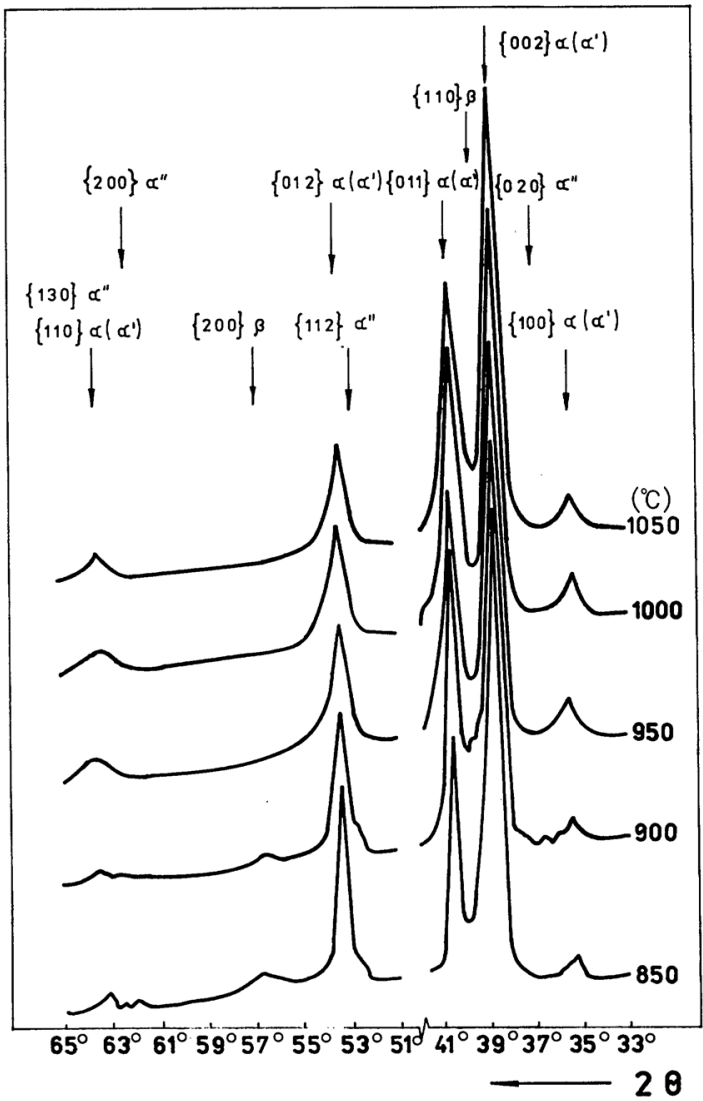

Fig. 2 X-ray diffractometer patterns for samples of the investigated $\mathrm{Ti}-7.5 \mathrm{Al}-2.5 \mathrm{Mo}-1.8 \mathrm{Cr}$ alloy. Parameter-quench temperatures in ${ }^{\circ} \mathrm{C}$. ing to room temperature depend strongly on the cooling rate and on the temperature of previous preheating of the sample.

$\mathrm{X}$-ray diffraction and metallographic examination of the samples cooled from 950,1000 or $1050^{\circ} \mathrm{C}$ at a rate of about $46.5 \mathrm{~K} / \mathrm{s}$ by quenching in water revealed the presence of the $\alpha^{\prime}$ martensite (Fig. 2 and Fig. 3(a)), whereas the structure obtained by water quenching from $850^{\circ} \mathrm{C}$ or $900^{\circ} \mathrm{C}$ contains the martensite $\alpha^{\prime \prime}$ in metastable equilibrium with $\alpha$ and $\beta$ phases (Fig. 2 and Fig. 3(b)). Replacing of the $\alpha^{\prime}$ by the $\alpha^{\prime \prime}$ martensite may result from the rhombic distortion of the lattice of martensite due to the greater enrichment of the parent phase $\beta$ in alloying elements. This is confirmed, among others, by the fact that with decreasing quenching temperature the diffraction maximum $\beta\{200\}$ shifts towards larger values of $2 \theta$ (Fig. 2).

Enrichment of the metastable $\beta$ phase in alloying elements can also cause the lowering of the $M_{s}$ temperature in a consequence of which the $\beta$ phase does not transform completely into martensite and remains to be pre-

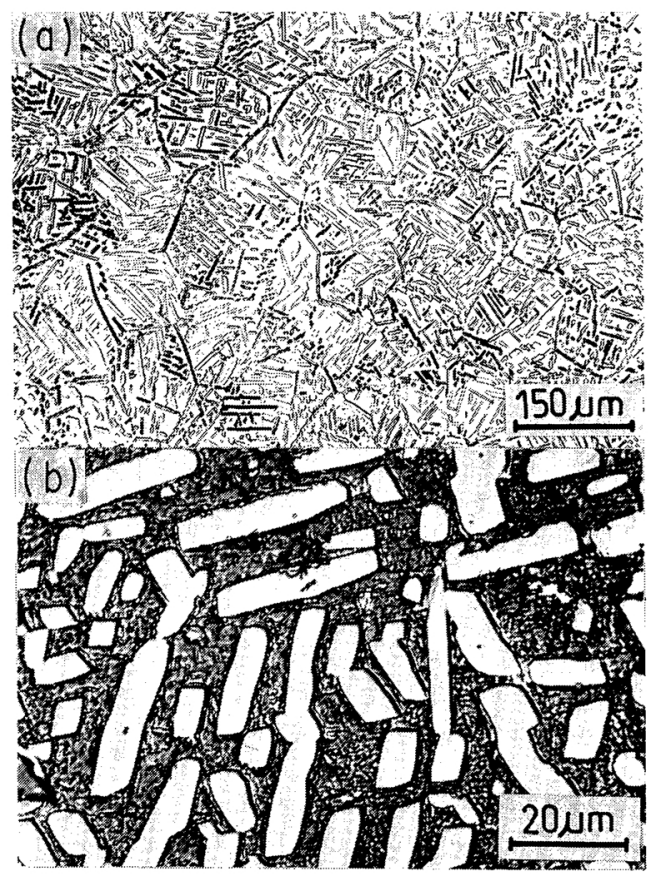

Fig. 3 Structure of the investigated alloy (a) after quenching from $950^{\circ} \mathrm{C}(1223 \mathrm{~K})$ at a rate of $46.5 \mathrm{~K} /$ $s$ and (b) after quenching from $850^{\circ} \mathrm{C}(1123 \mathrm{~K})$ at a rate of $18.8 \mathrm{~K} / \mathrm{s}$. 
sent in the structure of the alloy cooled from the $\alpha+\beta$ phase region.

Figure 4 shows the continuous-cooling transformation (CCT) phase diagram for the investigated alloy, determined experimentally on the basis of DTA and dilatometric investigations. Analysis of this diagram together with the structure shown in Fig. 5 indicates that during continuous cooling at a rate of about $19 \mathrm{~K} / \mathrm{s}$ the martensite transformation of the metastable $\beta$ phase is preceded by the processes of the precipitation of the $\alpha$ phase in the grain boundaries of the phase $\beta$. This leads to the enrichment of the remaining untransformed phase $\beta$ in alloying elements. The undercooled, enriched $\beta$ phase transforms subsequently diffusionless to the martensite $\alpha^{\prime \prime}$, similarly as in the case of quenching from the $\beta$ phase region, Decreasing of the cooling rate causes the lowering of the temperature at which the $\beta \rightarrow \alpha^{\prime \prime}$ transformation starts. This can be explained as the result of the increasing amount of the $\alpha$ phase precipitated from $\beta$ before its transformation into martensite $\alpha^{\prime \prime}$. The resulting enrichment of the $\beta$ phase in alloying elements, being higher at lower

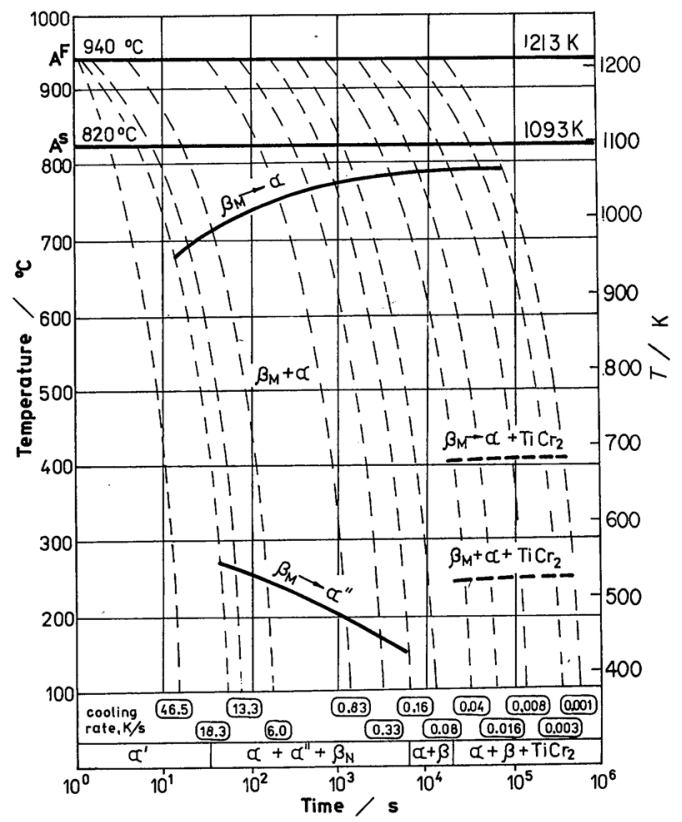

Fig. 4 Continuous cooling transformation (CCT) phase diagram for $\mathrm{Ti}-7.5 \mathrm{Al}-2.5 \mathrm{Mo}-1.8 \mathrm{Cr}$ alloy.
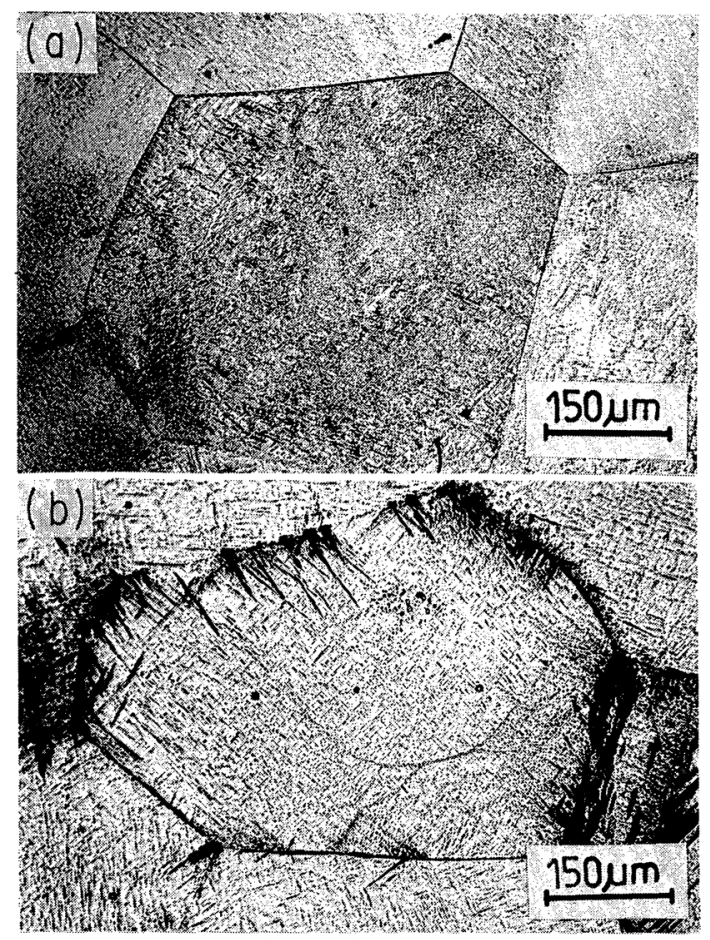

Fig. 5. Photomicrographs of the structure of investigated alloy (a) after quenching from $1000^{\circ} \mathrm{C}$ $(1273 \mathrm{~K}$ ) at a rate of $46.5 \mathrm{~K} / \mathrm{s}$ and (b) after cooling from $1000^{\circ} \mathrm{C}$ to $650^{\circ} \mathrm{C}(923 \mathrm{~K})$ at a rate of $18.8 \mathrm{~K} / \mathrm{s}$ and subsequent quenching in water.

cooling rates, causes the lowering of the temperature $\mathrm{M}_{\mathrm{s}}$ for the $\beta \rightarrow \alpha^{\prime \prime}$ transformation. The martensitic transformation $\beta \rightarrow \alpha^{\prime \prime}$ takes place during continuous cooling at rates ranging from about $19 \mathrm{~K} / \mathrm{s}$ to $0.16 \mathrm{~K} / \mathrm{s}$. At lower cooling rates $\beta$ decomposes omitting the martensitic transformation.

The results of the X-ray diffraction measurements confirm the sequence of the transformations given above, (Fig. 6). Additionally, the X-ray diffraction data indicate that after cooling at the rates ranging from $18.8 \mathrm{~K} / \mathrm{s}$ to $0.16 \mathrm{~K} / \mathrm{s}$ the $\beta$ phase remains to be present in the structure of the alloy. This $\beta$ phase can be formed as the result of the self-tempering of the $\alpha^{\prime \prime}$ martensite during cooling in the temperature interval between $M_{s}$ and room temperature. The presence of the $\beta$ phase may also result from the incomplete $\beta \rightarrow \alpha^{\prime \prime}$ transformation due to the lowering of the $\mathbf{M}_{\mathrm{f}}$ temperature below room temperature. In the first case the $\beta$ phase should 


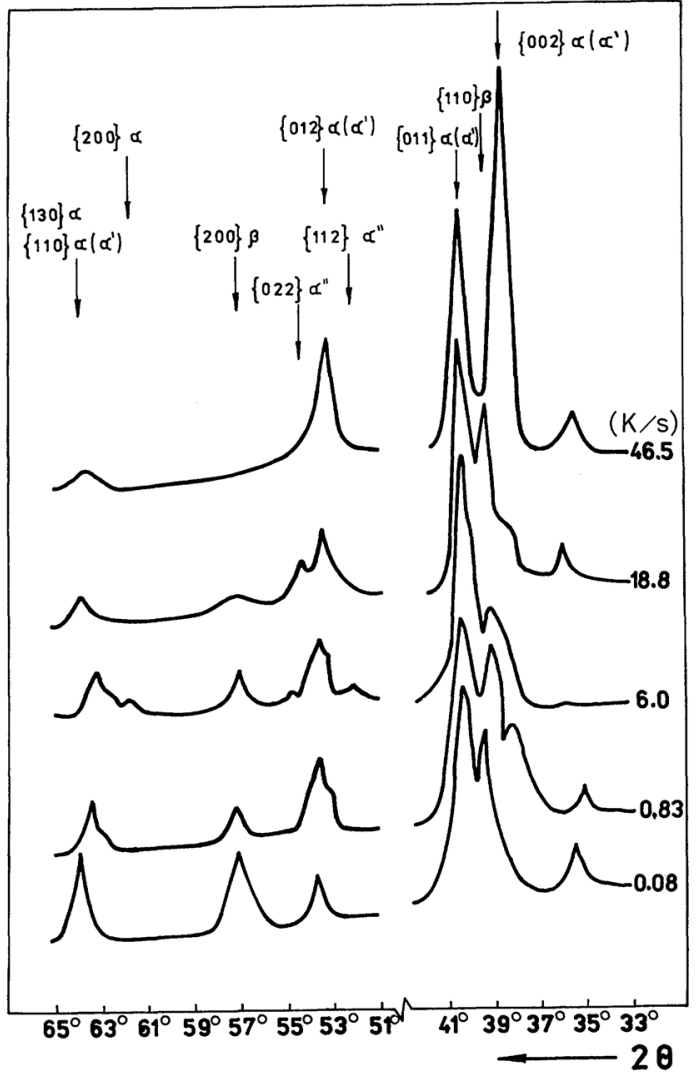

Fig. 6 X-ray diffractometer patterns for samples of the investigated alloy. Parameter-rate of the previous cooling from the $\beta$ phase region $\left(950^{\circ} \mathrm{C}\right)$ in $\mathrm{K} / \mathrm{s}$.

be relatively stable thus precluding their transformation during subsequent low-temperature tempering, whereas in the second case the decomposition of the retained $\beta$ phase should be observed as a result of the low-temperature tempering.

The results of the exoelectron emission investigations seem to support the last supposition. Figure 7 represents the experimental curves of the temperature dependence of the intensity of photostimulated exoelectron emission of samples cooled previously from the $\beta$ phase region $\left(950^{\circ} \mathrm{C}\right)$ at various cooling rates, recorded during subsequent heating at a constant rate of $0.25 \mathrm{~K} / \mathrm{s}$. For all the samples cooled at the rate of $18.8 \mathrm{~K} / \mathrm{s}$ or higher a maximum of the exoelectron emission intensity appears at about $260^{\circ} \mathrm{C}$. It is well known ${ }^{(13)(18)(19)}$ that under conditions we have fullfilled in our

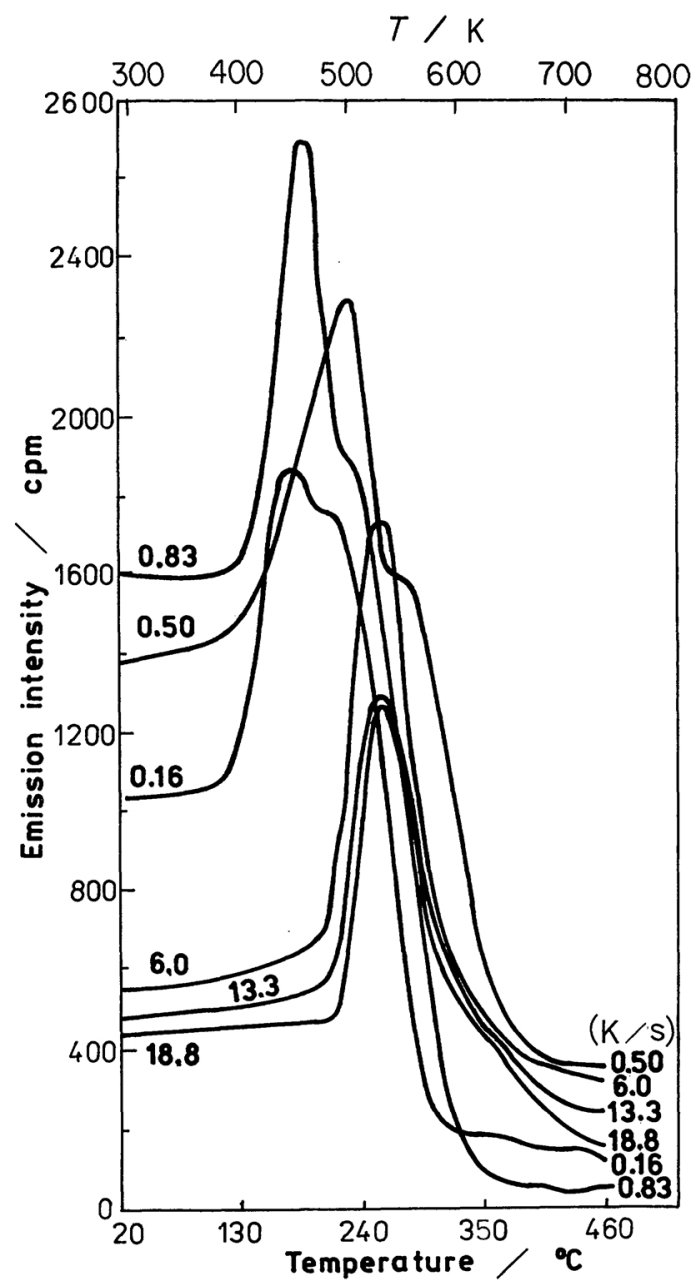

Fig. 7 Temperature dependence of the exoelectron emission intensity recorded during heating of the samples of investigated alloy. Parameter-rate (in $\mathrm{K} / \mathrm{s}$ ) of the previous cooling from the $\beta$ phase region.

measurements, the peaks of the exoelectron emission intensity result from the phase transformations occurring in the investigated sample. The maximum at $260^{\circ} \mathrm{C}$ is most probably connected with the decomposition of the metastable martensite $\alpha^{\prime \prime}$ leading in the final effect to the stable $\alpha$ and $\beta$ phases. Some additional results, not included in Fig. 7, indicate that the lower the cooling rate, the higher the intensity of this maximum. The last effect can be explained as the result of decreasing amount of the phase $\alpha^{\prime \prime}$ in the sample when the cooling rate increases. This agrees well with the results of 
our X-ray investigations as well as with the results published by Diakova and coworkers $^{(9)(10)}$.

For samples cooled at a rate of $0.83 \mathrm{~K} / \mathrm{s}$ or lower the maximum of exoelectron emission intensity at $260^{\circ} \mathrm{C}$ is preceded by an additional emission effect occurring in the temperature interval $130-200^{\circ} \mathrm{C}$. The exact determination of the maximal intensity of this effect is difficult because of the mutual overlapping of this effect with the effect occurring in the vicinity of $260^{\circ} \mathrm{C}$. This low-temperature maximum of the exoelectron emission intensity can be related to the decomposition of metastable $\beta$ phase, retained in measurable amount during the cooling at a rate of the order of $1 \mathrm{~K} / \mathrm{s}$. The product of the decomposition of the $\beta$ phase is, among others, the metastable $\alpha^{\prime \prime}$ phase, which in turn decomposes at about $260^{\circ} \mathrm{C}$ together with that originating directly during the cooling process. This is the reason for the observed increase of the intensity of the emission peak at $260^{\circ} \mathrm{C}$.

An initial value of the exoelectron emission intensity determined for the temperature interval $20-30^{\circ} \mathrm{C}$ is strongly dependent on the rate

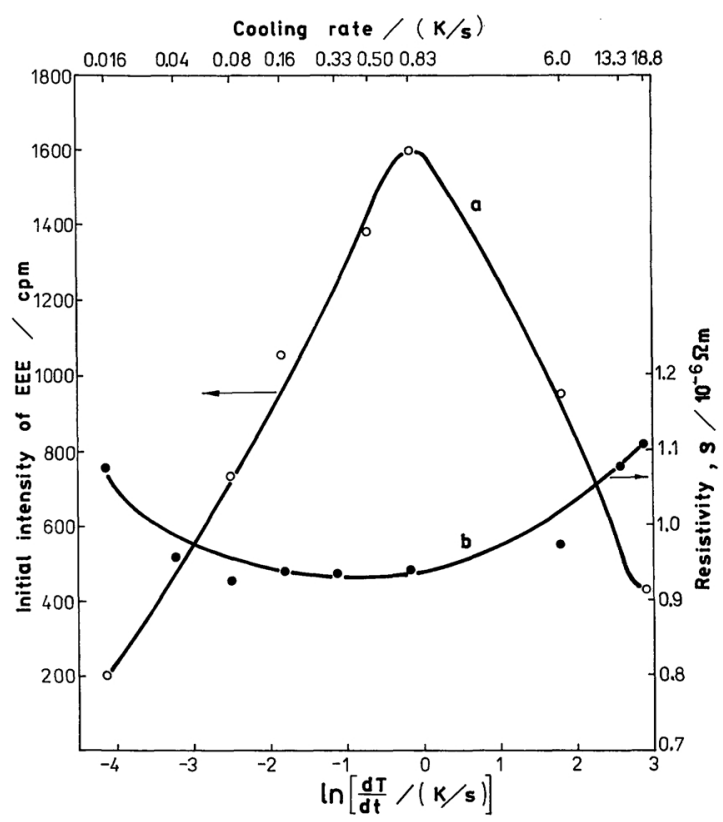

Fig. 8 Dependence of the initial intensity of exoelectron emission (a) and electrical resistivity (b) of the investigated alloy on the rate of cooling from the $\beta$ phase region. of the previous cooling from the $\beta$ phase region (Figs. 7 and 8). If the low-temperature exoelectron emission effect is really connected with the presence of the $\beta$ phase, the dependence of the initial emission intensity on the cooling rate can be interpreted as a qualitative representation of the influence of the cooling rate on the amount of $\beta$ phase retained in the sample. The results presented in Fig. 8 suggest that the amount of the $\beta$ phase in the investigated alloy increases with decreasing cooling rate reaching its maximal value after cooling at the rate of about $1 \mathrm{~K} / \mathrm{s}$. Further decrease of the amount of the $\beta$ phase with decreasing cooling rate results from the competing diffusive transformation $\beta \rightarrow \alpha$.

The results of exoelectron emission measurements agree well with those of electrical resistivity investigations which are presented in Fig. 8. As it is seen, the electrical resistivity measured at room temperature after cooling from the $\beta$ phase region initially decreases with decreasing cooling rate reaching its minimal value after cooling at a rate of about $0.8 \mathrm{~K} / \mathrm{s}$. Further decrease in the cooling rate causes an increase of the electrical resistivity of investigated alloy.

The complicated dependence of the electrical resistivity of multicomponent alloys on their structure and phase composition makes the interpretation of the observed dependence very difficult ${ }^{(21)}$. However, based on the regularity in the changes in the electrical resistivity on passing fro mthe $\mathrm{A} 3$ to the $\mathrm{A} 2$ type structure $\left(\rho_{\mathrm{A} 3}>\rho_{\mathrm{A} 2}\right)^{(22)}$ and taking into account the results of the exoelectron emission measurements, one can suppose that the observed changes in the electrical resistivity reflect the effect of cooling rate on the amount of the $\beta$ phase in the investigated alloy.

Changes in the structure and phase composition due to the continuous cooling at different cooling rates cause the changes in the mechanical properties of investigated material, measured at room temperature. As it is seen on the Fig. 9, all the tensile strength, proof strength and Vickers hardness are reaching their minimal value after cooling at a rate of about $0.08 \mathrm{~K} / \mathrm{s}$. At the same cooling rate the elongation and reduction of area are reaching its maximum 


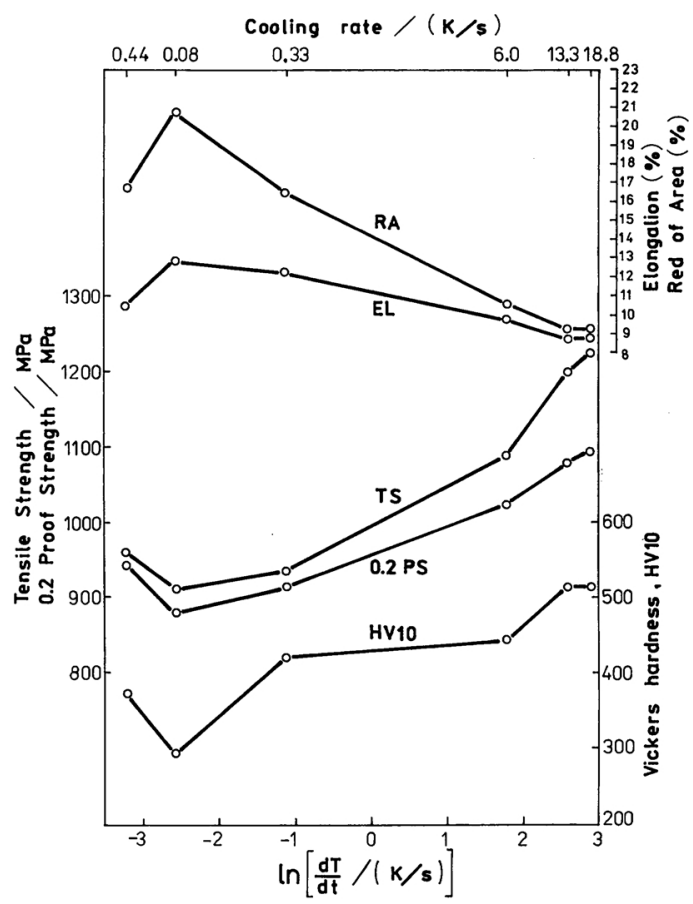

Fig. 9 Effect of the rate of continuous cooling from the $\beta$ phase region on the mechanical properties of $\mathrm{Ti}-7.5 \mathrm{Al}-2.5 \mathrm{Mo}-1.8 \mathrm{Cr}$ alloy.

value. The changes in the mechanical properties observed for the cooling rates ranging from $18.8 \mathrm{~K} / \mathrm{s}$ to $0.08 \mathrm{~K} / \mathrm{s}$ are most probably connected with increasing amount of the metastable $\alpha^{\prime \prime}$ and $\beta$ phases. The increase of the strength and hardness as well as worsening of the plasticity of the alloy after cooling at a rate lower than $0.08 \mathrm{~K} / \mathrm{s}$ may be ascribed to the presence of trace amount of the intermetallic compound $\mathrm{TiCr}_{2}$ forming as a result of eutectoidal decomposition of the chromium rich regions of the $\beta$ phase. The possibility of such a phase transformation in an alloy containing 0.3 mass $\%$ chromium or more has been demonstrated in a report ${ }^{(23)}$, however, the sensitivity of the experimental methods we have applied is too small to confirm or exclude the presence of the $\mathrm{TiCr}_{2}$ phase in the investigated material.

\section{Conclusions}

(1) The temperature interval of the $\alpha+\beta \rightarrow \beta$ transformation in the investigated alloy is relatively large. At a heating rate of $0.41 \mathrm{~K} / \mathrm{s}$ the transformation begins at about $820^{\circ} \mathrm{C}$ $(1093 \mathrm{~K})$ and ends at about $940^{\circ} \mathrm{C}(1213 \mathrm{~K})$. Above $940^{\circ} \mathrm{C}$ only the $\beta$ phase is present in the structure of the alloy.

(2) The phase composition of the asquenched alloy depends strongly on the quenching temperature. The samples quenched from the $\beta$ phase region in water contain the $\alpha^{\prime}$ martensite. Quenching from the two phase $(\alpha+\beta)$ region leads to the appearance of the martensite $\alpha^{\prime \prime}$.

(3) The kinetics of the decomposition of the $\beta$ phase depends on the cooling rate. At the rate of $46.5 \mathrm{~K} / \mathrm{s}$ the $\beta$ phase transforms to the $\alpha^{\prime}$ martensite, whereas after cooling at a rate from the interval $18.8-0.16 \mathrm{~K} / \mathrm{s}$ a mixture of $\alpha, \alpha^{\prime \prime}$ and $\beta$ phases is formed. Further lowering of the cooling rate leads to the decomposition of the $\beta$ phase omitting the martensitic transformation.

(4) Amount of the metastable phases in the structure forming after cooling from the $\beta$ phase region at rates ranging from 18.8 to $0.16 \mathrm{~K} / \mathrm{s}$ depends strongly on the cooling rate. Amount of the $\alpha^{\prime \prime}$ phase decreases monotonically with decreasing cooling rate, whereas the amount of the $\beta$ phase changes in a nonmonotonic manner reaching its maximum after cooling at a rate of about $0.83 \mathrm{~K} / \mathrm{s}$.

(5) Increasing amount of the metastable phases beneficially affects the hardness and strength of the investigated alloy and causes a worsening of its plasticity.

\section{REFERENCES}

(1) U. Zwicker: Titan und Titanlegierungen, SpringerVerlag, Berlin (1974), p. 000.

(2) B. A. Kolachev, V. A. Livanov and A. A. Bukhanova: Mekhanicheskie svojstva titana i yego splavov, Metallurgia, Moscow (1974).

(3) O. P. Solonina and S. G. Glazunov: Zharoprochnye titanovye splavy, Metallurgia, Moscow (1976).

(4) Phase Transformations in Titanium and its Alloys, Metallurgical Reviews, Imperial Metal Industries, Birmingam (1963).

(5) G. I. Nosova: Fazovye prevraschenia v splavach titana, Metallurgia, Moscow (1968).

(6) H. M. Otte: Mechanism of Martensitic Transformations in Titanium and Its Alloys, Pergamon Press, New York (1972).

(7) B. K. Wulf: Termicheskaya obrabotka titanovykh splavov, Metallurgia, Moscow (1969).

(8) B. A. Kolachev, V. A. Livanov and V. I. Elagin: 
Metallovedenie i termicheskaya obrabotka cvetnykh metallov i splavov, Metallurgia, Moscow (1972).

(9) M. A. Diakova, E. A. Lvova, I. N. Kaganovich, Z. F. Zvereva and L. S. Meschaninova: Izvestia AN SSSR Metally, No. 3 (1977), 142.

(10) M. A. Diakova, E. A. Lvova, T. G. Potemkina, I. N. Kaganovich, Z. F. Zvereva and L. S. Meschaninova: Fiz. metallov metalloved., 42 (1976), 333.

(11) V. S. Tomsinskii: Izv. VUZ. Cvet. Metallurgia, No. 5 (1977), 123.

(12) A. Bylica and J. Sieniawski: Rudy i Metale, 3 (1973), 116.

(13) T. Górecki and B. Sujak: Acta Phys. Polon., A42 (1966), 487.

(14) J. Stepniowski: Acta Phys. Polon., 30 (1966), 363.

(15) V. S. Tomsinskii and A. S. Ivanov: Fiz. metallov metalloved., 34 (1972), 429.

(16) A. S. Ivanov and V. S. Tomsinskii: Fiz. metallov metalloved., 36 (1973), 102.

(17) Powder Diffraction File Search Manual, Joint Committee on Powder Diffraction Standards, Pennsylvania (1975).

(18) B. Sujak and T. Górecki: Wiadomości Chemiczne, 27 (1972), 361.

(19) T. Górecki: Acta Universitatis Vratislaviensis; Matematyka, Fizyka, Astronomia, 272 (1976), 119.

(20) A. Klepacz, B. Król, S. Król, R. Matusik, A. Namysło and M.Tokarski:Materiały Konferencji Naukowej; Materiały na urządzenia energetyczne i technologiczne pracujące $w$ podwyższonych temperaturach, Katowice (1980) p. 329.

(21) J. M. Khatsinskaya, N. F. Lashko and M. J. Jermolova: Fiz. metallov metalloved., 30 (1970), 336.

(22) T. Górecki: Z. Metallk., 68 (1977), 231.

(23) J. Sieniawski: Doctor Thesis, Silesian University, Katowice (1978). 